\title{
A PRÁTICA DA AUTOCOMPOSIÇÃO: UM CAMINHO COMPARATIVO ENTRE A ESCOLA INSTRUMENTALISTA E CONSTITUCIONAL DEMOCRÁTICA DO PROCESSO
}

\section{Resumo}

Igor Benevides Amaro Fernandes* Carlos Marden Cabral Coutinho**

O presente trabalho tem por objetivo discutir a autocomposição, especialmente, a mediação e a conciliação no âmbito do Poder Judiciário através da Teoria Constitucionalista com ênfase para o conceito de Modelo Constitucional de Processo (Andolina e Vignera). Para tanto, pretende-se traçar uma passagem pelas teorias do processo, a iniciar pela Teoria da Relação Jurídica (Oskar Von Bülow), a qual foi superada pela Teoria Estruturalista (Elio Fazzalari) pela representação ideal do fenômeno processual. Houve ainda exposição crítica sobre a Teoria Instrumentalista (Cândido Rangel Dinamarco) em face de adotar um conjunto de conceitos incompatíveis com o Estado Democrático de Direito.

Palavras-chave: Autocomposição. Poder Judiciário. Teoria Constitucionalista. Modelo Constitucional de Processo. Estado Democrático de Direito.

\section{THE PRACTICE OF AUTOCOMPOSITION: A WAY OF COMPARISON BETWEEN THE INSTRUMENTALIST SCHOOL AND PROCESS DEMOCRATIC CONSTITUTIONAL}

\begin{abstract}
The present work aims to discuss the autocomposição, especially, mediation and conciliation in the judiciary through the Constitutionalist Theory with emphasis to the concept of Process Constitutional Model (Andolina and Vignera). For this purpose, we intend to draw a passage by the process theories, start by the Legal of Relationship Theory (Oskar Von Bülow), which was overtaken by Structuralist Theory (Elio Fazzalari) by the ideal representation of procedural phenomenon. There were also critical exposure on the Instrumentalist Theory (Cândido Rangel Dinamarco) in the face of adopting a set of concepts that are incompatible with the Democratic Rule of Law.
\end{abstract}

Keywords: Autocomposição. Judiciary Branch. Constitutionalist Theory. Process Constitutional Model. The Democratic Rule of Law.

\footnotetext{
* Mestrando em Processo e Direito ao Desenvolvimento no Programa de Pós-Graduação Stricto Sensu do Centro Universitário Christus (Unichristus). Especialista em Gerência Executiva de Marketing (UFC). Graduado em Direito e em Publicidade e Propaganda (Unifor). Email: benevides.igor@gmail.com

** Pós-doutorando em Estado, Democracia e Constituição (Unisinos). Doutor em Direito Processual (PUC Minas). Mestre em Ordem Jurídica Constitucional (UFC). Especialista em Processo Civil (UFC). Graduado em Direito (UFC). Procurador federal, professor e pesquisador do Programa de Pós-Graduação Stricto Sensu do Centro Universitário Christus (Unichristus). E-mail: carlosmardencc@hotmail.com
} 


\section{INTRODUÇÃO}

O conflito é algo inerente à própria natureza humana, logo, presente na vida social. O Direito precisa ser entendido com certo dinamismo e os litígios necessitam de maior acompanhamento em busca do melhor resultado para as partes. Pode-se afirmar ainda que o acesso à justiça é amplo, sob a ótica de um direito constitucional assegurado a todo e qualquer cidadão. Destaca-se que existe uma inquietação da sociedade no que tange ao tempo total dispendido desde o momento em que se ajuíza uma ação no Poder Judiciário até seu efetivo trânsito em julgado.

Diante de tal perspectiva, surge o interesse pelo estudo dos métodos de autocomposição no âmbito processual. Todavia, merece destacar que o tempo processual, de acordo com Marden (2015), deve ser entendido como aquele lapso temporal que corresponde ao tempo necessário para a prática de atos processuais imprescindíveis em busca de se atingir a finalidade processual. De que valeria a pena, portanto, buscar uma extrema rapidez processual, todavia, o acordo não garantir direitos fundamentais aos litigantes?

Desta forma, o objetivo geral deste trabalho é analisar o papel da autocomposição como mecanismo previsto no próprio Código de Processo Civil de 2015, sem desconsiderar a obediência aos princípios constitucionais, tal como a duração razoável do processo. Assim, resta assegurar uma devida proteção aos direitos fundamentais dos litigantes, não do ponto de vista meramente instrumental, mas a partir de um Modelo Constitucional de Processo.

\section{AUTOCOMPOSIÇÃO E SUA RELAÇÃO COM A DURAÇÃO RAZOÁ VEL DO PROCESSO}

De acordo com o que se depreende do art. $5^{\circ}$, LXXVIII, CF/88, o qual foi acrescido a partir da EC no 45 de 08 de dezembro de 2004, não se pode conceber que o acesso à justiça corresponda somente ao ingresso em juízo. O grande problema que atinge diretamente o Poder Judiciário atualmente diz respeito ao intuito de se obter uma prestação jurisdicional célere, impulsionando, assim, uma maior preocupação na aplicação de mecanismos de saída do conflito do Judiciário, a chamada desjudicialização dos conflitos ${ }^{1}$.

\footnotetext{
${ }^{1}$ É preciso compreender a relação entre tempo e processo a partir da conjugação da necessidade de tempo para adoção da série de atos concatenados que constituem o processo e angústia do interessado com a passagem de tempo em relação a uma suposta resolução por autotutela, conforme entendimento de Marden (2015, p.103).
} 
A partir do entendimento de Fiorelli J., Fiorelli M., e Malhadas Junior (2008), os métodos de gestão de conflitos são divididos em autocompositivos e heterocompositivos. Nos métodos autocompositivos, as partes almejam uma solução para o conflito sem a decisão de um terceiro, sendo exemplos, a mediação e a conciliação. Já nos métodos heterocompositivos, a solução do conflito é tarefa de um terceiro, ou seja, é de sua responsabilidade determinar o que as partes devem ou não fazer, sendo exemplos, o juiz Estatal (Poder Judiciário) e o árbitro (procedimento arbitral).

Inicialmente, merece destacar que a mediação e a conciliação, muitas vezes, ainda são vistas como instrumentos voltados para a solução de conflitos. De certa forma, tal perspectiva ganhou maior força no Brasil, a partir da edição da Resolução no 125/2010, do Conselho Nacional de Justiça (CNJ), bem como pela entrada em vigor da Lei $\mathrm{n}^{\circ}$ 13.105/2015 (Código de Processo Civil) e da Lei nº 13.140/2015 (Lei de Mediação), porém, certas ressalvas merecem destaque, principalmente, no que diz respeito à qualidade do acordo e garantia de direitos fundamentais entre os litigantes.

$\mathrm{O}$ art. $3^{\circ}, \S 3^{\circ}$ do Código de Processo Civil de 2015 prevê que, tanto a mediação quanto a conciliação devem ser estimuladas, sempre que possível, por magistrados, advogados, defensores públicos, membros do Ministério Público. Assim sendo, percebe-se a importância que tais mecanismos têm adquirido no Direito Processual Brasileiro.

Conforme Sales (2004), vale salientar que a mediação se trata de um método de autocomposição assistida, em face de as próprias partes discutirem e comporem as controvérsias, no qual o mediador, considerado uma terceira pessoa imparcial, visa facilitar a comunicação entre elas através de técnicas próprias.

Fiorelli J., Fiorelli M., e Malhadas Junior (2008) definem a mediação como método mais recomendável no que diz respeito às situações consideradas crônicas, entendidas estas, como as que possuem elevado envolvimento emocional e necessidade de preservar os relacionamentos a partir de uma leitura dos acontecimentos, podendo ser aplicada na área ambiental, comunitária, vizinhança e cível, dentre outras. Logo, a relação é de colaboração por se tratar de um procedimento amigável baseado na política do ganha-ganha para ambas as partes.

Segundo Orsini e Silva (2016), nos conflitos em que há desequilíbrio entre os litigantes, o papel do mediador é procurar equilibrar a balança e oferecer oportunidades de forma que ambos dialoguem em condições semelhantes. Percebe-se que uma mediação regida pelo clima desequilibrado entre os litigantes, tende a não obter êxito. Assim sendo, resta claro 
que o papel do mediador é possibilitar um diálogo efetivo e sustentável de maneira a envolver todos no processo de mediação.

Outro mecanismo de solução de conflitos similar à mediação é a conciliação, porém, cabe mencionar certas diferenças ${ }^{2}$. Sales (2010) preceitua que a conciliação conta com o auxílio de um terceiro imparcial chamado conciliador, o qual tem a função de aproximar as partes, controlar as negociações, sugerir e formular propostas, bem como apontar vantagens e desvantagens com o fito de se realizar um acordo efetivo.

Diante disso, o conciliador interfere na discussão entre as partes, sugerindo e propondo soluções para o conflito que as partes podem aceitar ou não ${ }^{3}$. Assim, adota uma postura mais ativa. Já na mediação, não há essa interferência, tendo em vista que as partes conflitantes sugerem as soluções e o mediador é apenas um facilitador do diálogo.

Dias e Faria (2016) afirmam ainda que a mediação e a conciliação são considerados métodos de autocomposição bilaterais preponderantes no ordenamento jurídico por possibilitarem às próprias partes na busca por soluções para seus conflitos, com poder de decisão, sem a necessidade de um terceiro (alheio ao litígio) atuar como julgador. Consideram ainda que os mecanismos de autocomposição retromencionados podem e devem ser utilizados antes mesmo de ser provocada a jurisdição (heterocomposição), logo, cabem ser adotados tanto de forma endoprocessual (durante o trâmite de uma ação) ou extraprocessual (extrajudicialmente). Por fim, tratando-se ainda das diferenças existentes entre mediação e conciliação, merece destacar o Quadro 1 abaixo, com o fito de explanar, de forma mais concisa, as peculiaridades de tais mecanismos:

Quadro 1 - Diferenças existentes entre a conciliação e a mediação

\begin{tabular}{|c|c|c|}
\hline $\mathbf{N}^{\mathbf{0}}$ & CONCILIAÇÃO & MEDIAÇÃo \\
\hline 01 & $\begin{array}{c}\text { Construção de propostas de acordo entre } \\
\text { as partes }\end{array}$ & $\begin{array}{c}\text { Desconstrução do conflito e restauração da } \\
\text { convivência pacífica entre as pessoas }\end{array}$ \\
\hline 02 & Atendimento das demandas pessoais & Busca de satisfação e benefícios mútuos \\
\hline 03 & Repercussão da solução sobre si mesmo & $\begin{array}{c}\text { Repercussão da solução sobre terceiros - } \\
\text { filhos, empregados, comunidade, etc. }\end{array}$ \\
\hline 04 & Coautoria de soluções construídas pelas & Autoria da solução pelas partes com mero \\
\hline
\end{tabular}

\footnotetext{
$2 \mathrm{O}$ art. $165, \S \S 2^{\circ}$ e $3^{\circ}, \mathrm{CPC} / 15$ estabelece a diferença entre o papel do conciliador e do mediador.

5 Pode-se afirmar que os tipos de conflitos mais adequados à solução pelo mecanismo da conciliação são aqueles nos quais as partes envolvidas não possuem vínculo afetivo, emocional anterior. Exemplo disso são os casos de colisão de veículos, de questões relacionadas a recálculo de dívidas, etc.
} 


\begin{tabular}{|c|c|c|}
\hline 05 & $\begin{array}{c}\text { partes e conciliador - conciliador oferece } \\
\text { sugestões e propostas }\end{array}$ & $\begin{array}{c}\text { auxílio do mediador - vedado ao } \\
\text { mediador, sugerir, opinar ou propor }\end{array}$ \\
\hline 06 & $\begin{array}{c}\text { Foco no presente, na responsabilidade } \\
\text { pelo evento e correção das consequências }\end{array}$ & $\begin{array}{c}\text { Abordagem multidisciplinar - questões } \\
\text { sociais, emocionais, legais, financeiras, } \\
\text { etc. }\end{array}$ \\
\hline 07 & Pauta objetiva - matéria e substância & passado volte a ser manejado. \\
\hline 08 & Publicidade & Pabjetiva - relação interpessoal \\
\hline 09 & $\begin{array}{c}\text { Parecer técnico pode ser dado pelo } \\
\text { conciliador, caso seja apto }\end{array}$ & $\begin{array}{c}\text { Parecer técnico pode ser buscado com } \\
\text { especialistas }\end{array}$ \\
\hline 10 & $\begin{array}{c}\text { Advogados são defensores dos interesses } \\
\text { dos seus clientes }\end{array}$ & $\begin{array}{c}\text { Advogados são assessores legais e } \\
\text { consultores dos seus clientes }\end{array}$ \\
\hline
\end{tabular}

Fonte: Almeida (2009, p. 85-93)

Em face da abordagem até então discutida em relação à mediação e à conciliação como métodos de gestão de conflitos autocompositivos, denota-se que ainda são pouco utilizados como forma de "desafogar" o Poder Judiciário, visando uma maior efetividade e celeridade processual, tendo em vista que atualmente é grande o acúmulo de processos, principalmente, na Justiça Estadual brasileira de $1^{\circ}$ grau ${ }^{4}$, onde se concentra a maior preocupação, já que o grande problema não é de entrada, mas sim, de saída, ou seja, é o tempo que o litígio leva para sair do Poder Judiciário.

Todavia, ressalta-se que é preciso ter muito cuidado com a questão do tempo em face da "síndrome da pressa" colocar em risco a garantia de direitos fundamentais aos litigantes, por exemplo. Diante desse cenário, merece destacar os dados obtidos no Poder Judiciário do Estado do Ceará na Semana da Conciliação em 2015, a partir do trabalho desenvolvido pelo Núcleo Permanente de Métodos Consensuais de Solução de Conflitos (NUPEMEC), o qual tem utilizado a mediação e a conciliação na solução de conflitos.

Denota-se, com base no Quadro 2 abaixo, a quantidade de acordos realizados na Semana da Conciliação em 2015, totalizando capital e interior do Estado do Ceará. A partir de uma melhor análise dos dados, denota-se que a maior preocupação ainda é com o aspecto quantitativo e não qualitativo na aplicação dos mecanismos de solução de conflitos, em especial, a mediação e a conciliação, os quais, muitas vezes, confundem-se na prática.

Quadro 2 - Semana da Conciliação 2015 


\begin{tabular}{|l|c|}
\hline \multicolumn{1}{|c|}{ AUDIÊNCIAS } & ESTADO DO CEARÁ \\
\hline Total Geral de Audiências Agendadas & 21.735 \\
\hline Total Geral de Audiências Realizadas & 14.218 \\
\hline Total de Acordos & 5.817 \\
\hline Percentual de Acordos & $40,91 \%$ \\
\hline
\end{tabular}

Fonte: TJCE (2015)

Logo, percebe-se que o objetivo precípuo é a obtenção de um maior número possível de acordos realizados para bater meta e compor os Relatórios do próprio Conselho Nacional de Justiça (CNJ), ocorrendo, em determinadas situações, de os próprios litigantes chegarem a ser coagidos na feitura de acordos, resultando, portanto, em acertos mal realizados que infringem a garantia de direitos fundamentais, tão importantes em um Estado Democrático de Direito, sob a perspectiva de um Modelo Constitucional de Processo.

Por sua vez, Silva (2013) corrobora com a ideia de que o papel do conciliador é apresentar sugestões na justa medida da objetividade do conflito que está tratando e cabe-lhe estimular as partes a elaborarem suas próprias soluções. Porém, não é permitido a tal profissional que estimule os litigantes mediante coação psicológica, tendo em vista que não está autorizado a forçar ou pressionar as partes para que realizem determinado acordo, já que tais práticas comprometem a idoneidade do próprio meio.

Merece destacar que há uma tendência de aumento nos referidos percentuais, tendo em vista que o Código de Processo Civil de 2015 já entrou em vigor, prevendo a realização de audiência de conciliação e mediação como etapa obrigatória, anterior à formação da lide, como regra geral para todos os processos cíveis. No entanto, denota-se também, nas próprias audiências, a importância pela busca de acordos bem feitos e que possam ser efetivados na prática, de forma a não levar em consideração a ideia de que a solução mais rápida seria a melhor opção para atendimento ao princípio da duração razoável do processo ${ }^{5}$.

Conforme o entendimento de Marden (2015, p. 165):

Percebe-se, portanto, que a duração razoável não é aquela que atende o anseio por resposta imediata que acomete os interessados no processo. Se, por um lado, é legítimo que os interessados não admitam a existência de processos cuja resposta

\footnotetext{
${ }^{4}$ Dados relevantes do CNJ (2015, p.90) indicam que a taxa de congestionamento na Justiça Estadual brasileira compara o que não foi baixado com o que tramitou durante o ano base (soma dos casos novos e dos casos pendentes iniciais). Diante disso, constatou-se que a taxa de congestionamento de $1^{\circ}$ grau (76\%) supera em 29 pontos percentuais a taxa de congestionamento do $2^{\circ}$ grau (47\%).

5 Por meio de tal perspectiva, pode-se afirmar ser necessário buscar um tempo considerado razoável na aplicação dos mecanismos autocompositivos, sem ofender os princípios e garantias fundamentais presentes no Modelo Constitucional de Processo.
} 
parece nunca vir (deixando assim em aberta a situação entre as partes), por outro lado o legislador não deve se comover com o sentimento intuitivo que as partes têm de que a resolução poderia ter sido mais rápida, vez que nem todas as configurações procedimentais são admissíveis em um Estado Democrático de Direito.

O art. 319, VII, CPC/15 trouxe a opção do autor pela realização ou não de audiência de conciliação ou de mediação em atenção ao princípio da autonomia da vontade das partes, o qual tem um procedimento descrito no art. 334, CPC/15, além de inovação trazida pela possibilidade de mediação nas ações que envolvem manutenção e reintegração de posse e nas ações de família, conforme arts. 565 e 694, CPC/15 respectivamente.

Dias e Faria (2016) preceituam que somente a expressa manifestação bilateral de desinteresse por parte do autor e do réu, gera o cancelamento da audiência de mediação ou de conciliação designada. Caso apenas uma das partes manifeste o desinteresse, a audiência será mantida, devendo ambos comparecer ao ato, ficando passível de a ausência ser considerada ato atentatório à dignidade da justiça, com a aplicação de multa, conforme preceitua o art. $334, \S 4^{\circ}$ e $8^{\circ}, \mathrm{CPC} / 15$.

A partir da reflexão suscitada, caberia no próximo tópico tratar da perspectiva do processo como metodologia de garantia dos direitos fundamentais, perpassando de maneira comparativa entre a Escola Instrumentalista e Constitucional Democrática do Processo.

\section{AUTOCOMPOSIÇÃO SOB A ÓTICA DA ESCOLA INSTRUMENTALISTA E CONSTITUCIONAL DEMOCRÁTICA DO PROCESSO}

A evolução da ciência processual ocorreu a partir de Oskar Von Bülow, em 1868, na Alemanha, através da Teoria da Relação Jurídica, a qual auferia que o processo, na sua forma intrínseca, era entendido como uma relação jurídica e, na sua forma extrínseca, como procedimento, entendido este como a representação da forma de manifestação exterior do processo. Diante de tal concepção, existia um vínculo pessoal entre os sujeitos do processo e uma ideia implícita de autoridade na figura do juiz ${ }^{6}$.

A Teoria da Relação Jurídica, a qual foi superada pela Teoria Estruturalista ${ }^{7}$ de Elio Fazzalari pela representação ideal do fenômeno processual, serviu de base para a Escola

\footnotetext{
6 Importante contribuição de Coutinho (2012, p.26) na explicação da origem do Direito Processual para melhor compreensão do aspecto evolutivo.

7 Relevante a compreensão sobre a definição de processo a partir da visão de Fazzalari (2006, p.118-119) como um procedimento do qual participam (são habilitados a participar) aqueles em cuja esfera jurídica o ato final é destinado a desenvolver efeitos: em contraditório, e de modo que o autor do ato não possa obliterar as suas atividades. Portanto, o processo é uma sequência de atos concatenados, ou seja, é procedimento em contraditório.
} 
Instrumentalista de Cândido Rangel Dinamarco ${ }^{8}$, em 1982, no Brasil, a partir das contribuições de Klein e Wach, Chiovenda, Carnelutti e Liebman.

A partir do entendimento da Escola Instrumentalista, Dinamarco (2008) apresenta o processo como instrumento da jurisdição com a finalidade de se buscar a pacificação social e concretização de uma ordem jurídica justa, aferida a partir dos chamados escopos metajurídicos do Estado (social, político e jurídico). Assim sendo, denota-se um caráter autoritário e intervencionista deste último através da figura do próprio juiz, herdado desde as bases da Teoria da Relação Jurídica de Bülow.

De acordo com a linha espaço-tempo processual construída, percebe-se que, no Brasil, Jorge Neto (2016) afirma que o processo judicial é visto sob a ótica de um instrumento com a finalidade de ter ganhos econômicos e financeiros e não apenas para a solução de disputas verdadeiras (aquelas em as pessoas envolvidas apresentam sinceras dúvidas sobre como os fatos ocorreram ou sobre como a Lei deve ser interpretada e aplicada).

Diante de tal visão, vale a reflexão de que é necessário vincular o magistrado à concepção de que o processo não deve ser considerado um fim em si mesmo, já que sua função não é achar a melhor solução para o caso concreto, mas garantir direitos fundamentais.

Gonçalves (2012) preceitua que a doutrina processual brasileira tem admitido maior preocupação em atribuir escopos jurídicos, éticos e sociais ao processo. Nesta seara, o grande nome de destaque coube a Cândido Rangel Dinamarco.

Nesta esteira de raciocínio construído, Marden (2015, p. 126) assim preceitua:

[...] Ora, se o objetivo do processo é absorver o conflito existente no seio da sociedade e lhe oferecer uma solução, de forma a pacificar os envolvidos, então quanto menos tempo o processo durar, menor será o tempo durante o qual haverá insegurança e insatisfação. Se o processo resume a ser instrumento da jurisdição, não há outra conclusão possível senão aquela segundo a qual o tempo processual vai ser pensado exclusivamente a partir da ideia de operacionalidade.

Pensar, portanto, o processo como um instrumento que tem a função de solucionar conflitos e que almeja dar uma resposta rápida para a sociedade é ter visão, de certa forma, limitada em relação ao Direito Processual pelo fato de o processo não possuir finalidade de resolver problemas, já que, se assim fosse, qualquer litígio iria sempre recair no Poder Judiciário e o tempo processual seria pensado exclusivamente a partir da ideia de operacionalidade.

\footnotetext{
8 Professor respeitado nacional e internacionalmente e autor de estudos de Direito Processual e da Obra "A Instrumentalidade do Processo".
} 
Assim sendo, trazendo essa interpretação para o aspecto da autocomposição, Sales (2010) menciona que, dentre os vários objetivos da mediação, destaca-se a prevenção da má administração de conflitos, a inclusão social e a paz social. Por essa razão, denota-se que o referido mecanismo autocompositivo, diante de tais objetivos, encontra aproximação com a Escola Instrumentalista Processual quando almeja tratar da prevenção de conflitos e inclusão social na busca pela paz social.

Todavia, de acordo com Sales (2010), a mediação preventiva tem caráter transformador que ultrapassa o objetivo do simples acordo entre as partes para modificar uma relação entre elas, passando da relação de uma disputa para uma de colaboração a partir do estabelecimento de uma comunicação harmônica com o fito de mitigar conflitos futuros. Assim sendo, não se pode, diante de tal perspectiva, ter uma visão instrumentalista da mediação, ao considerá-la como um mecanismo restrito, o qual possui o intuito de realizar acordos rápidos como forma de desafogar o Poder Judiciário.

Seguindo a linha de raciocínio, Grinover (2008) assevera que a democracia é considerada o fundamento a reger, igualmente, a conciliação e a mediação, em razão de serem formas de concretização da participação cidadã dos próprios litigantes na administração da Justiça.

Demarchi (2008, p.61) destaca ainda que:

Outro aspecto da autocomposição de litígios que reforça a natureza democrática da conciliação e da mediação é o fato de tais procedimentos respeitarem a autonomia da vontade dos cidadãos, haja vista que as partes litigantes "nunca são obrigadas a celebrar qualquer tipo de acordo e não devem ser de qualquer forma constrangidas a celebrar acordo que não se coaduna com sua refletida vontade.

Vale ressaltar ainda o que defende Gonçalves (2012, p. 150), a partir de sua visão de instrumentalidade técnica processual:

[...] nessa perspectiva do Direito contemporâneo, não poderia, jamais, significar a técnica se desenvolvendo para se produzir a si mesma. A instrumentalidade técnica do processo está em que ele se constitua na melhor, mais ágil e mais democrática estrutura para que a sentença que dele resulta se forme, seja gerada, com a garantia da participação igual, paritária, simétrica, daqueles que receberão os seus efeitos.

Nessa perspectiva, não se deve trazer a concepção instrumentalista de que o acordo deve ser o mais rápido possível, mas sim, que a autocomposição (mediação e conciliação) deve ser vista sob a ótica democrática de processo.

Segundo Gutierrez e Cunha (2015), o caráter democrático pode ser ressalvado a partir do princípio da autonomia da vontade das partes, o qual é considerado um dos 
elementos essenciais da democracia, onde os cidadãos voltados a um regime político são tratados e reconhecidos como pessoas livres e iguais em direitos e obrigações.

De acordo com Marden (2015), a preocupação excessiva com a celeridade é justificada com base na efetividade do processo, tendo em vista que se parte da premissa de que processo demorado não atinge a sua finalidade. Isso seria uma visão muito instrumental e mereceria a ressalva de que a efetividade não decorre da celeridade, mas sim da capacidade do processo de atingir seu objetivo constitucional, ou seja, garantir o devido processo constitucional ${ }^{9}$.

Partindo desta perspectiva, Coutinho (2012), defende que o processo passou a ser percebido além do seu caráter instrumental, assim considerando, como sendo ele próprio um direito fundamental diante do que preceitua o art. 5\%, XXXV, CF/88 (a lei não excluirá do Poder Judiciário lesão ou ameaça a direito).

Diante de tal ótica, o Modelo Constitucional de Processo de Andolina e Vignera surgiu em 1992 na Itália, sendo composto pelos princípios constitucionais com o fito de garantir direitos fundamentais, tais como o contraditório, a ampla defesa, a duração razoável do processo, a fundamentação das decisões, a publicidade e a imparcialidade. Percebe-se, portanto, que o conteúdo do referido Modelo é assegurado pelo art. $5^{\circ}, \mathrm{CF} / 88$, sendo assim caracterizado por Andolina e Vignera (1997, p. 09):

\begin{abstract}
Prima di prendere in considerazione i singoli elementi (oggettivi e soggettivi) del modelo costituzionale del processo civile, è doveroso evidenciare in questa sede i suoi caratteri generali, che possono individuarsi: a) nella espansività, consistente nella sua idoneità $[\ldots]$ a condizionare la fisionomia dei singoli procedimenti giurisdizionale introduttidal legislatore ordinario[...]; b-) nella variabilità, indicante la sua attitudine ad assumere forme diversa di guisa che I'adeguamento al modello costituzionale [..] delle figura processuali concretamente funzionanti puó avvenire secondo varie modalità in vista de perseguimiento di particolari scopi; c-) nella perfettibilità, designante la sua idoneità ad essere perfeizonato dalla legislazione subcostituzionale, la quale [...] ben puó costruire procedimenti giurisdizionale carratterizzati da (ulterior) garantiza ed istituti ignotà al modello costituzionale[...].
\end{abstract}

Pode-se afirmar que o Modelo Constitucional de Processo tem vínculo forte com a Constituição de 1988 e suas características são voltadas para o referido escopo, tais como: a expansividade (o Modelo vai se espalhar por todo o ordenamento jurídico), a adaptabilidade (o processo pode ser adaptável a qualquer procedimento, desde que não contrarie o Modelo Constitucional de Processo) e a aperfeiçoabilidade (o Modelo pode ser aperfeiçoado, desde que não contrarie o que preceitua a Carta Magna). 
Freitas (2013) afirma que entender o Modelo Constitucional de Processo é analisá-lo sob a perspectiva da disciplina principiológica constitucional, desconsiderando a concepção limitada do processo como relação jurídica entre juiz, autor e réu e de que este seria o instrumento da jurisdição.

Logo, o Modelo Constitucional de Processo considera a Constituição como norma jurídica que tem supremacia no ordenamento jurídico (a partir de uma visão Kelseniana) e tais normas vinculam o legislador ordinário, onde, aquelas que tratam de processo, formam um sistema chamado Modelo Constitucional e qualquer procedimento configurado pelo legislador deve, obrigatoriamente, adaptar-se a tal Modelo, sob pena de ser considerado inválido.

Ao aproximar o retromencionado Modelo, dos mecanismos de autocomposição, Orsini e Silva (2016, p. 26-27) entendem que:

[...] o mediador deve proporcionar aos mediados condições para que estes participem de forma consciente no processo mediativo, tendo noção dos direitos ali envolvidos e das consequências de suas decisões. Tem-se, assim, uma nova concepção de mediador, que passa a estar imbricado na metodologia da mediação como um defensor pluriparcial dos Direitos Humanos-fundamentais que perpassam pela situação conflituosa em discussão, favorecendo e beneficiando não apenas a uma das partes, mas a todas que carecerem de auxílio no sentido de proteger e assegurar a reivindicação e defesa de seus direitos. A pluriparcialidade, portanto, estaria mais afeita a um ideal de mediação para o acesso ampliado à justiça.

Neste ponto, cabe ressaltar que seria um grande avanço adotar o Modelo Constitucional aplicado aos mecanismos de autocomposição, refletindo, com isso, em uma nova concepção de mediação e conciliação através da preservação de direitos fundamentais, o que geraria, consequentemente, na maior satisfação dos litigantes através de acordos com maiores níveis de qualidade, rompendo, assim, com a ideia de que tais mecanismos se aplicariam apenas para dar celeridade às demandas, ou seja, com finalidade limitada apenas ao aspecto cronológico através da já denominada “síndrome da pressa".

Conforme Baracho (2008), a partir das contribuições herdadas de Andolina e Vignera de Modelo Constitucional de Processo, assegura, mediante sua Teoria Constitucionalista, que as garantias constitucionais do processo devem alcançar todos os participantes do mesmo, mediante a consagração de princípios de direito processual, a partir do reconhecimento e a enumeração de direitos da pessoa humana.

Freitas (2013) entende que os estudos da Teoria Constitucionalista do Processo surgem a partir da superação da Teoria da Relação Jurídica entre autor, juiz e réu e da Escola

${ }_{9}^{9}$ Marden (2015, p. 203) entende que é aquele configurado nos termos do modelo constitucionalmente previsto, de modo que o processo não pode ser tão demorado que venha a comprometer a sua efetividade e/ou gerar prejuízo para as partes, assim como não poderá ser tão apressado que não seja permitido às partes o exercício de seus direitos fundamentais. 
Instrumentalista, a qual entende o processo como mero instrumento da jurisdição. Além disso, destaca-se também uma complementação da Teoria Estruturalista de Elio Fazzalari.

Denota-se, portanto, que Alfredo Baracho foi uma referência ao movimento mediante o entendimento de que é a forma mais compatível de processo em face do Estado Democrático de Direito, qual seja, o de democracia, podendo ser aplicado como melhor opção no que tange à aplicação aos mecanismos de autocomposição, em especial, a mediação e a conciliação.

\section{CONSIDERAÇÕES FINAIS}

Merece destacar que o acesso à justiça é direito assegurado a todos os cidadãos, ou seja, o Estado tem o dever de prestar a jurisdição a todos, no entanto há problemas tais como morosidade, lentidão processual, incapacidade dos operadores jurídicos em face das novas realidades surgidas.

Destaca-se ainda que os problemas enfrentados pelo Poder Judiciário sempre existiram, porém, ganharam posição de maior relevância nos últimos anos, sendo tal cenário percebido em relação à capacidade de regular e solucionar conflitos. Diante de tal perspectiva construída, vale mencionar que há dificuldade de comportar todas as demandas existentes, tendo em vista que a quantidade de lides é muito grande.

Pode-se afirmar que o problema do acesso à Justiça não é uma questão de "entrada", pois, pela porta grandiosa desse templo chamado Justiça, entra quem quer, seja através de advogado pago ou mantido pelo Poder Público. Assim sendo, a maior dificuldade é no que tange à "saída" do conflito do Poder Judiciário, tendo em vista que poucos conseguem sair num prazo razoável.

Percebe-se que a questão da legitimidade do Poder Judiciário vem sendo discutida desde o início da década de 1980, no quesito celeridade, levando em conta o tempo para solução definitiva do conflito. Logo, é comum confundir duração razoável com duração mínima, a partir de uma ideia de tempo muito simplificada. Em razão disso, pode-se afirmar que não é possível buscar a simplicidade e a eficácia processuais em razão da "síndrome da pressa", tão prejudicial ao Estado Democrático de Direito através dos mecanismos de autocomposição, em especial, a mediação e a conciliação.

A repercussão de tal pensamento reflete, por exemplo, na utilização dos mecanismos retromencionados previstos no Código de Processo Civil de 2015 para realização de acordos 
que não se preocupam com o aspecto qualitativo, mas apenas quantitativo, já que tendem a se limitarem ao cumprimento de metas estabelecidas pelo Conselho Nacional de Justiça, fruto de uma sociedade hipermoderna que se submete a uma constante pressão por resultados quantitativos.

Desta forma, analisar o papel da autocomposição sem desconsiderar a obediência aos princípios constitucionais, tal como a duração razoável do processo é de extrema importância ao Estado Democrático de Direito. Além disso, a positivação dos direitos fundamentais trouxe grandes alterações na seara de estudo do Direito Processual, em face de estabelecer uma relação estreita de vinculação entre o processo e a Constituição Federal de 1988, já que se tem em mente que todo processo é constitucional estando sujeito à Supremacia da Carta Magna.

Todavia, denota-se, a partir da evolução das Escolas Processuais, que nenhum campo da ciência cresceu sozinho, mas foi algo construído a partir das contribuições dadas por cada Teoria Processual, para assim chegar, ao Modelo Constitucional, considerado o mais aplicado ao Estado Democrático de Direito, sendo fruto de muitas conquistas históricas e normativas.

Ressalta-se ainda, que o conhecimento passa por transformações, a fim de acompanhar a própria vida em sociedade, restando claro que os conceitos que respondiam a uma realidade normativa do século XIX não são mais adequados para responder à realidade normativa do mundo de hoje.

Diante disso, analisar o processo a partir de um Modelo Constitucional, é pensá-lo sob a característica da expansividade, adaptabilidade e aperfeiçoabilidade, o qual serviu de base para a construção de uma Teoria Constitucionalista. Diante deste contexto, passa a ser compreendido como garantidor de direitos fundamentais e, consequentemente, vai romper com a Teoria da Relação Jurídica de Oskar Von Bülow.

Portanto, não caberia conceber mais o processo como relação jurídica entre as partes, conferindo excesso de poderes aos magistrados, bem como não seria mais viável determinar que o ato judicante ainda seja abordado como instrumento posto à disposição do Estado para atingir escopos metajurídicos por via de atividade resumida ao julgador.

Logo, resta deixar de lado o papel de uma instrumentalidade meramente técnica e passar a compreender o processo diante das diretrizes do Estado Democrático de Direito através da devida proteção aos direitos fundamentais dos litigantes a partir de um Modelo Constitucional de Processo.

O referido Modelo assegura que o provimento deve ser construído por meio das alegações, argumentações e produções probatórias dos litigantes e com o devido exercício das 
garantias fundamentais, cabendo destaque para o contraditório, a ampla defesa, a duração razoável do processo, a fundamentação das decisões, a publicidade e a imparcialidade.

Por fim, a partir da discussão obtida com este trabalho, resta assegurar uma devida proteção aos direitos fundamentais das partes a partir do papel democrático desempenhado pelos mecanismos de autocomposição por meio da ótica da Teoria Constitucionalista, resultante do Modelo Constitucional de Processo, após evolução das Teorias do Direito Processual brasileiro.

Resta assim, diante de tal cenário, buscar uma maior utilização dos mecanismos autocompositivos em prol da efetivação de direitos fundamentais.

\section{REFERÊNCIAS BIBLIOGRÁFICAS}

ALMEIDA, Tania. Mediação e conciliação: dois paradigmas, duas práticas diversas. In: CASELLA, Paulo Borba; SOUZA, Luciane Moessa de (Coord.). Mediação de conflitos: novos paradigmas de acesso à justiça. Belo Horizonte: Forum, 2009, p.85-93. Disponível em: <https://www.academia.edu/22380472/Mediação_de_conflitos_novo_paradigma_de _acesso_à_justiça>. Acesso em: 12 jun. 2017.

ANDOLINA, Ítalo; VIGNERA, Giuseppe. I fondamenti costituzionali della giustizia civile: Il modello costituzionale del proceso civile italiano. 2. ed. Torino: G. Giappichelli Editore, 1997.

BARACHO, José Alfredo de Oliveira. Direito Processual Constitucional: aspectos contemporâneos. Belo Horizonte: Fórum, 2008.

BRASIL. Constituição (1988). Constituição da República Federativa do Brasil. Brasília, DF: Senado, 1988.

. Lei n ${ }^{\circ} 13.105$, de 16 de março de 2015. Código de Processo Civil. Diário Oficial da União, Brasília, DF, de 17 de março de 2015.

Lei $n^{\circ} 13.140$, de 26 de junho de 2015. Dispõe sobre a mediação entre particulares como meio de solução de controvérsias e sobre a autocomposição de conflitos no âmbito da administração pública; altera a Lei no 9.469, de 10 de julho de 1997, e o Decreto no 70.235, de 6 de março de 1972; e revoga o $§ 20$ do art. 6 o da Lei no 9.469, de 10 de julho de 1997. Diário Oficial da União, Brasília, DF, de 29 de junho de 2015.

Emenda Constitucional $\mathrm{n}^{\mathrm{0}}$ 45, de 30 de dezembro de 2004. Altera dispositivos dos arts. $5^{\circ}, 36,52,92,93,95,98,99,102,103,104,105,107,109,111,112,114,115,125,126$, 127, 128, 129, 134 e 168 da Constituição Federal, e acrescenta os arts. 103-A, 103B, 111-A e 130-A, e dá outras providências. Diário Oficial da União, Brasília, DF, de 31 de dezembro de 2004.

Rev. de Processo, Jurisdição e Efetividade da Justiça | e-ISSN: 2525-9814| Maranhão | v. 3 | n. 2 | p. 20 - 35| Jul/Dez. 
Resolução no 125 de 29/11/2010. Dispõe sobre a Política Judiciária Nacional de tratamento adequado dos conflitos de interesses no âmbito do Poder Judiciário e dá outras providências. Disponível em: 〈http://www.cnj.jus.br/busca-atos-adm?documento=2579>. Acesso em: 07 jun. 2017.

CEARÁ. Tribunal de Justiça do Estado do Ceará (TJCE). Relatório Global Totalização. Semana da Conciliação 2015. Disponível em: <http://10.1.1.143/conciliacao/ paginas/RelatorioConciliacao3.asp>. Acesso em: 01 mar. 2017.

CONSELHO NACIONAL DE JUSTIÇA (CNJ). Justiça em Números 2015: ano-base 2014. Brasília, 2015. Disponível em: <http://www. cnj.jus.br/programas-e-acoes/pj-justica-emnumeros>. Acesso em: 08 ago. 2017.

COUTINHO, Carlos Marden Cabral. Processo (Constitucional): reconstrução do conceito à luz do paradigma do Estado Democrático de Direito. Revista Opinião Jurídica, Fortaleza, v. 10, n. 14, p.24-41, 2012. Anual. Disponível em: <http://periodicos.unichristus.edu.br/index. php/opiniaojuridica/article/view/804/274>. Acesso em: 20 jun. 2017.

DEMARCHI, Juliana. Técnicas de conciliação e mediação. In: GRINOVER, Ada Pellegrini; WATANABE, Kazuo; LAGRASTE, Caetano (Coords.). Mediação e gerenciamento do processo: revolução na prestação jurisdicional. São Paulo: Atlas, 2008, p. 61.

DIAS, Luciano Souto; FARIA, Kamila Cardoso. A Mediação e a Conciliação como Métodos Autocompositivos no Contexto do Código de Processo Civil de 2015. Revista Forense, Rio de Janeiro, v. 423, n. 112, p.147-171, jan./jun. 2016. Semestral.

DINAMARCO, Cândido Rangel. A Instrumentalidade do Processo. 13. ed. São Paulo: Malheiros, 2008.

FAZZALARI, Elio. Instituições de Direito Processual. Campinas: Bookseller, 2006.

FIORELLI, José Osmir; FIORELLI, Maria Rosa; MALHADAS JUNIOR, Marcos Julio Olivé. Mediação e solução de conflitos: teoria e prática. São Paulo: Atlas, 2008.

FREITAS, Gabriela Oliveira. O Processo Constitucional como garantia dos direitos fundamentais no Estado Democrático de Direito. Lex Humana: Revista do Programa de Pós-Graduação em Direito da Universidade Católica de Petrópolis, Petrópolis, v. 5, n. 1, p.57-77, 2013. Coimbra University Press. http://dx.doi.org/10.14195/2175-0947_5-1_4. Disponível em: <https://digitalis-dsp.uc.pt/bitstream/10316.2/33679/1/LH5-1_artigo4.pdf? ln=pt-pt>. Acesso em: 23 jun. 2017.

GONÇALVES, Aroldo Plínio. Técnica Processual e Teoria do Processo. 2. ed. Belo Horizonte: Del Rey, 2012.

GRINOVER, Ada Pellegrini. Os fundamentos da justiça conciliativa. In: GRINOVER, Ada Pellegrini; WATANABE, Kazuo; LAGRASTE, Caetano (Coords.). Mediação e 
gerenciamento do processo: revolução na prestação jurisdicional. São Paulo: Atlas, 2008, p. 05 .

GUTIERREZ, Daniel Mota; CUNHA, Jânio Pereira da. Jurisdição Processual e Democracia: advento da audiência de conciliação e de mediação, efetivação dos meios equivalentes e acesso à Justiça. Revista Opinião Jurídica, Fortaleza, v. 13, n. 17, p.108-131, 2015. Anual. Disponível em: <http://periodicos.unichristus.edu.br/index.php/opiniaojuridica/article/view/ 495/193>. Acesso em: 22 jun. 2017.

JORGE NETO, Nagibe de Melo. Abrindo a Caixa Preta: Por que a Justiça não funciona no Brasil?. Salvador: Juspodivm, 2016.

MARDEN, Carlos. A Razoável Duração do Processo: o fenômeno temporal e o modelo constitucional processual. Curitiba: Juruá, 2015. 224 p.

ORSINI, Adriana Goulart de Sena; SILVA, Nathane Fernandes da. A Pluriparcialidade como Novo Elemento da Mediação: repensando a atuação do mediador a partir das noções de neutralidade, imparcialidade e equidistância. Revista Opinião Jurídica, Fortaleza, v. 14, n. 19, p.13-32, 2016. Semestral. Disponível em: <http://periodicos.unichristus.edu.br/index.php/ opiniaojuridica/article/view/909/384>. Acesso em: 20 jun. 2017.

SALES, Lilia Maia de Morais. Justiça e Mediação de Conflitos. Belo Horizonte: Del Rey, 2004.

Mediare: um guia prático para mediadores. 3. ed. Rio de Janeiro: GZ, 2010.

SILVA, Érica Barbosa e. Conciliação judicial. Brasília: Gazeta Jurídica, 2013, p. 173. 